\title{
The Dangers of using Intention as a Surrogate for Retention in Brand Positioning Decision Support Systems
}

\author{
Michel Ballings and Dirk Van den Poel
}

\begin{abstract}
The purpose of this paper is to explore the dangers of using intention as a surrogate for retention in a decision support system (DSS) for brand positioning. An empirical study is conducted, using structural equations modeling and both data from the internal transactional database and a survey. The study is aimed at evaluating whether the DSS recommends different product benefits for brand positioning when intention is used as opposed to retention as a criterion variable. The results show that different product benefits are recommended contingent upon the criterion variable (intention vs. retention). The findings also indicate that the strength of the structural relationships is inflated when intention is used. This study is limited in that it investigates only one industry; the newspaper industry. This study provides guidance for brand managers in selecting the most appropriate benefit for brand positioning and advices against the use of intention as opposed to retention in DSS. To the best of our knowledge this study is the first to challenge and refute the commonly held belief that intention is a valid surrogate for retention in a DSS for brand positioning.
\end{abstract}

\section{Introduction}

Given an ongoing evolution from transaction-based marketing to relationship-based marketing (Grönroos 1997), that is primarily driven by the assertion that selling an additional product to an existing customer is several times less expensive than selling the product to a new customer (Rosenberg and Czepiel 1984), it has been argued that building enduring bonds with customers is a profitable strategy (Reichheld

\footnotetext{
Michel Ballings

Department of Marketing, Ghent University, Ghent, Belgium, e-mail: Michel.Ballings@UGent.be

Dirk Van den Poel

Department of Marketing, Ghent University, Ghent, Belgium, e-mail: Dirk.VandenPoel@UGent.be
} 
1996). Hence customer retention has gained a central role in marketing strategies (Buckinx et al. 2007).

One way of reducing churn, or driving retention, is establishing brand associations in consumers' minds (brand- positioning) (Keller and Lehmann 2006) that have been shown to be positively linked to retention (Reynolds et al. 2001). In order to find these associations, and subsequently use them as building blocks in their brand positioning, companies resort to decision support systems (DSSs). A successful DSS consists in a model that enables marketing professionals to determine the brand-positioning that would reinforce the relationship between a provider and a customer. Because this requires linking attitudinal variables to behavior, and extant literature has shown that this link is hierarchical in nature (Shim and Eastlick 1998), a structural equations model is in order (e.g., brand positions influence attitudes such as product satisfaction and brand commitment that in turn influence retention). Although retention should be the criterion variable in these models, research has focused on survey measures of behavior leaving observed behavior lingering in the background (e.g., Homer and Kahle (1988). This can severely bias inferences (see Bolton 1998 and Morwitz 1997 for details).

Although gains are made along several fronts (e.g. Milfont et al. 2010), the link between high level bases for brand positioning and observed behavior still remains unexplored. In this study we build on the studies Homer and Kahle (1988), Shim and Eastlick (1998), and Milfont et al. (2010) and assess the impact on the final brandpositioning recommendation of using observed behavior (retention) as opposed to declared behavior (intention) as the criterion variable. More specifically, the question is whether different values or benefits are recommended for brand positioning contingent upon whether the dependent variable is declared or observed.

\section{Conceptual model}

Schwartz' value inventory is a comprehensive framework consisting of 10 basic human values (see Schwartz and Boehnke 2004). It is widely used in industry for brand positioning. Literature indicates that value groupings depend on the context (see Schwartz and Boehnke 2004 and Homer and Kahle 1988). From our analysis, we see a three factor solution emerging: (1) power and achievement, (2) hedonism and selfdirection and (3) tradition, conformity and security. The values Stimulation, Universalism and Benevolence display cross loadings on two factors and thats why we eliminate them from the analysis. In this study we will call the three emerging factors (1) self-enhancement, (2) openness to change and (3) conservation and we will level our hypotheses at this structure. Allen and Meyer's (1990) three-component model of commitment consists of normative commitment (social obligation based bond- ought to), affective commitment (emotional desire based bond- want to) and calculative or continuance commitment (rational cost based or need based bondneed to). Meyer et al. (2002) find, in an organizational context, that all three forms of commitment are negatively related to turnover intentions. Whereas commitment 
concerns the brand, involvement concerns the product class (Zaichowsky 1994; Ros et al. 1999). A person that identifies with either the product (involvement), or the brand (commitment) will be less likely to churn (Sjöberg and Sverke 2000). Research suggests that affective commitment might also affect normative commitment (see Ros et al. 1999 and Meyer et al. 2002). There is ample evidence of a positive relationship between satisfaction and behavioral intentions (Cronin and Taylor 1992) and of commitment's mediating role of the relationship between satisfaction and intentions (Paul 2009). Meta-analytic research points out that overall job satisfaction positively correlates with affective commitment and normative commitment (Meyer et al. 2002). Adversely, a small negative relationship is reported between satisfaction and continuance commitment (Meyer et al. 2002). Hence, we formulate the hypotheses as follows:

- H1: Affective commitment has a positive impact on renewal intentions.

- H2: Normative commitment has a positive impact on renewal intentions.

- H3: Calculative commitment has a positive impact on renewal intentions.

- H4: Involvement has a positive impact on renewal intentions.

- H5: Affective commitment has a positive influence on normative commitment.

- H6: Satisfaction has a positive impact on affective commitment.

- H7: Satisfaction has a positive impact on normative commitment.

- H8: Satisfaction has a small negative impact on calculative commitment.

Several authors found support for the relationship between values on the one hand and attitudes (Homer and Kahle 1988) and declared behavior (Shim and Eastlick 1998) on the other hand. Overall satisfaction then, is an evaluation of outcomes relative to a certain expected internal or external standard. Consequently, when thinking about possible relationships with satisfaction we have to keep substitutes (e.g. the internet) in mind. Because the purpose of this study is to discover which benefits display the strongest link to intention (retention), and subsequently satisfaction and involvement we will not hypothesize about which link is strongest.

- H9: Self-Enhancement is related to satisfaction.

- H10: Openness- to- change is related to satisfaction.

- H11: Conservation is related to satisfaction.

- H12: Self-Enhancement is related to involvement.

- H13: Openness to change is related to involvement.

- H14: Conservation is related to involvement.

\section{Empirical study}

\subsection{Sample}

The customers of two Belgian newspaper brands were invited to participate in a study. Both brands can be considered similar, except their geographical targeting 
at the province/state level. One of the two brands consisted of different editions. 25897 emails were sent out, inviting customers to click on a link to go to an online questionnaire (an incentive in the form of a prize was offered). 2142 of them reached the end of the questionnaire and were subsequently used in the analysis.

\subsection{Measures}

Except for observed retention all constructs used items measured with a 7-point Likert scale. To acquire an accurate translation, all measures were translated to Dutch and back-translated to English by two independent translation agencies. We used the Short Schwartz's Value Survey (Lindeman and Verkasalo 2005) and the following introductory question: Imagine a typical moment at which you are reading [newspaper brand]. In general, how do you feel at that moment? Indicate to which degree the following concepts are consistent with that feeling. All measurement scales are based on extant literature: renewal intentions (Lindeman and Verkasalo 2005), normative commitment (Ros et al. 1999), calculative commitment (Gounaris 2005), affective commitment (Gustafsson et al. 2005), and satisfaction (Fornell 1996). Benefits, satisfaction, commitment and intention are all measured at time t, to predict retention at time $\mathrm{t}+1$. The time window appears in Fig. 1 .

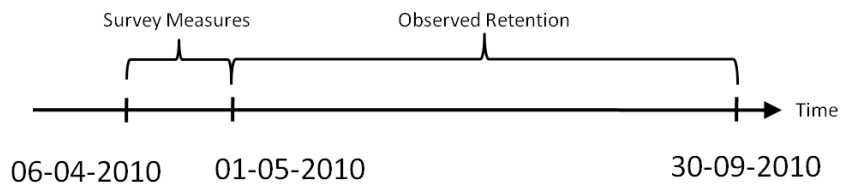

Fig. 1 Time window

Consistent with the approach of Gustafsson et al. (2005), we computed retention from the account data as the number of days a customer is retained. The average retention is 141.70 days (standard deviation $=34.37$ ).

\subsection{Analysis and results}

In order to test our hypotheses we used the procedure of structural equation modeling proposed by Anderson and Gerbing (1988). This procedure was applied in AMOS, version 18. Because our data is multivariate non-normal we cannot use a normal theory estimator such as ML or GLS. Hence we estimated the model parameters using weighted least squares which is an asymptotic distribution free method (Browne 1984), making no assumptions of normality. 
The final model is displayed in Fig. 2. All direct paths in the final model were significant (at least at the $\mathrm{p}<.05$ level) for the intention model. To compare it with the retention model we left all relationships in the model.

Cronbach's Alpha for the (latent) variables ranges from 0.721 to 0.954 with an average of 0.871 . The standard deviations range from 0.963 to 1.582 for the Likert scales indicating a substantial amount of variance to be explained. The correlations range from 0.198 to 0.952 with a mean of 0.563 . The mean of retention is 141.7 and the standard deviation is 34.37 . In the following, we estimate the model using structural equation modeling.

The squared multiple correlations (SMC) reveal that a considerable amount of variance is explained by the model: intention (retention): 0.396 (0.010), overall satisfaction $=0.627(0.637)$, calculative commitment $=0.350(0.366)$, normative commitment $=0.777(0.778)$, affective commitment $=0.908(0.896)$, involvement: 0.198 (0.215). Consistent with extant literature (Hennig-Thurau and Klee (1997); Newman and Werbe (1973)) only a very low amount of variance is explained in retention. In terms of model fit, both models are very much alike: intention (retention) : Chi-square (385):1081.424 (1046.501), Chi-square/DF: 2.809 (2.718), AGFI: 0.824 (0.835), GFI: 0.854 (0.863), PGFI: 0.707 (0.715), CFI: 0.782 (0.791), PNFI: 0.621 (0.627), RMSEA: 0.029 (0.028).

As the results show (Fig. 2), all hypotheses are supported, except hypothesis 3, 5, 8, 12 and 14. In what follows we'll provide possible explanations. H3 predicted a positive influence of calculative commitment on renewal intentions. As Meyer et al. (2002) point out, calculative commitment is the weakest commitment predictor of intentions. Consequently we deem it is plausible that the relationship becomes insignificant when modeled together with affective and normative commitment. Related to this, our analyses indicated that calculative commitment has a positive influence on normative commitment. Although correlation analysis (not shown in this paper) already confirmed this link, the construct of satisfaction, modeled as a common predictor of both normative and calculative commitment seems to substantiate this link. This relationship seems plausible; a rational cost-based motivation, perceived as a need to stay does not take into account the other side's interests and can be considered as taking unfair advantage of the partner. This can induce feelings of guilt and indebtedness toward the partner and a sense of obligation to return a favor. As such, calculative commitment can influence normative commitment. This line of reasoning is consistent with the other findings; as expected, the reverse link between calculative and normative commitment is not true, nor is there a relationship between calculative commitment and affective commitment.

H5 predicted a positive influence of affective commitment on normative commitment. Although correlation analysis (not shown in this paper) clearly supports this hypothesis, structural equations modeling, which is a much stronger test of the hypothesis, clearly does not. Our analyses point to the fact that satisfaction acts as a suppressor variable, rendering the hypothesized relationship insignificant. This effect has never been reported, presumably because no author has proposed a link between satisfaction and normative commitment. 
H8, foresaw a negative link between satisfaction and calculative commitment. As aforementioned, this link was expected to be small, indicating a lack of connection. In contrast, both the correlation analysis and structural equation model indicate a positive link between satisfaction and calculative commitment, but, admittedly, smaller than the link between satisfaction and the other commitment constructs. A positive link seems plausible, because satisfied customers' lack of involvement with how to end the relationship, and the associated costs, may drive this positive relationship. Moreover, a positive connection between satisfaction and lack of worthwhile alternatives also seems justified in that satisfaction measures, among others, the brands performance relative to competitors. Finally tests of $\mathrm{H} 12$ and 14 indicated a lack of relationship between self-enhancement and involvement and conservation and involvement. This hiatus is probably due to the strong link between opennessto-change and involvement, accounting for the majority of the correlation.

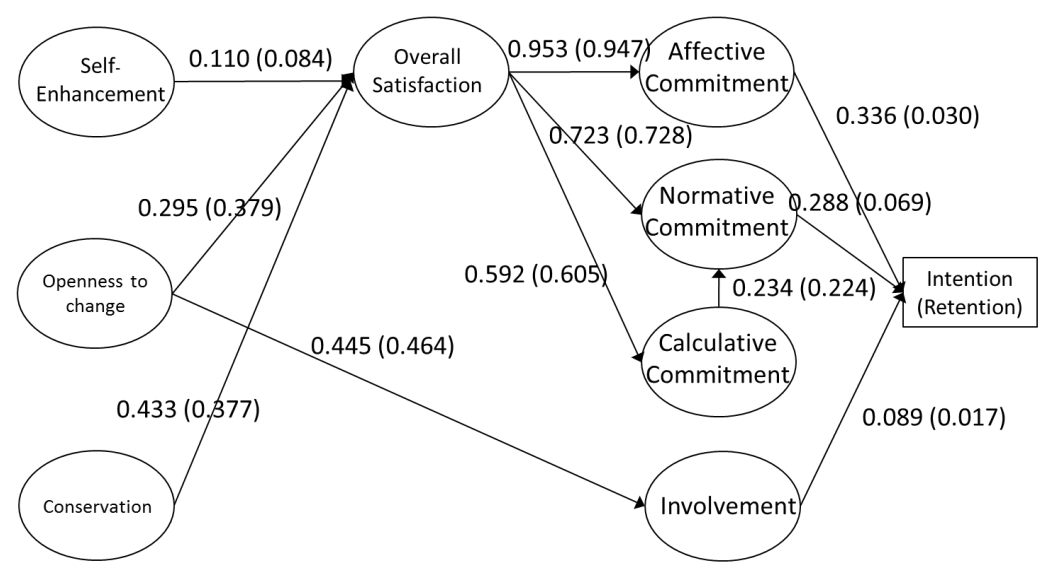

Fig. 2 Estimated model

Finally, having discussed the validity of our model, we arrivie at the main question of this study: the standardized total effects of the values/benefits on intention (retention) is as follows: Self Enhancement 0.063, p $<0.30$ (0.007, p $<0.20)$, Openness to change $0.207, \mathrm{p}<0.40(0.041, \mathrm{p}<0.05)$ and Conservation $0.245, \mathrm{p}<0.05$ $(0.033, \mathrm{p}<0.05)$. In the following section well discuss these findings.

\section{Discussion}

The purpose of the decision support system in this study is to make a recommendation about which value should serve as the primary benefit for brand positioning. When using intention as a dependent variable the recommendation is Conservation 
with 0.245 (which is $18.7 \%$ higher than the value second in position, i.e., Opennessto-change 0.207 ), but when using retention it is the inverse, namely Openness-tochange with 0.041 (which is $24.24 \%$ higher than the second in position, i.e., Conservation with 0.033 ). Using intention as a proxy for retention will not only overestimate the strength of the relationship between benefits and retention but will provide erroneous recommendations that are based on a $18.7 \%$ difference. Given the fact that the practice of brand positioning involves substantial communications budget at the one hand and drives sales on the other hand this could be a serious threat to brands. If the wrong brand position is chosen, the wrong associations and expectations may be created in the consumer's mind, which may inflict permanent damage to a brand's performance in the market. Although survey measures are easier to obtain, we advise against their use as a surrogate for observed retention in decision support systems for brand positioning.

\section{Future research and limitations}

A direction for further research is modeling other dependent variables, such as acquisition, up-sell or cross-sell. Although brands should display a certain level of consistency to come across trustworthy, core values and subsequently positions are dynamic and evolve over time (McCracken 2005). It is highly important to monitor this evolution. Managers could just as well choose to position their brand based on customer acquisition if it is first launched, reposition it based on cross-sell when it is in the maturity stage and reposition it based on retention when the brand is in the decline phase. For example, if a car maker notices that its brand positioned on the value power is entering the decline phase, it might be time to reposition the brand on values that drive retention (e.g., green and efficiency). This study is limited in that it is restricted to one industry (the newspaper business). Another direction for future research is replication in other industries.

\section{References}

ALLEN, N. J. and MEYER, J. P. (1990): The measurement and antecedents of affective, continuance, and normative commitment to the organization. Journal of Occupational Psychology, 63, 1, 1-18.

ANDERSON JC. and GERBNG DW. (1988): Structural equation modeling in practice: a review and recommended two-step approach. Psychological Bulletin, 103, 3, 41123.

BOLTON, R. N. (1998): A dynamic model of the duration of the customers relationship with a continuous service provider: the role of satisfaction. Marketing Science, 17, 1, 45-65. BROWNE, M. W. (1984): Asymptotically distribution-free methods for the analysis of covariance structures. British Journal of Mathematics and Statistical Psychology, 37, 62-83. BUCKINX, W., VERSTRAETEN, G. and VAN DEN POEL, D. (2007): Predicting customer loyalty using the internal transactional database. Expert Systems with Applications, 32, 125 134. 
CRONIN, J. J. Jr. and TAYLOR, S. A. (1992): Measuring service quality: a reexamination and extension. Journal of Marketing, 56, 3, 55-68.

FORNELL, C., JOHNSON, M.D., ANDERSON, EW., et al. (1996): The American customer satisfaction index: nature, purpose, and findings. Journal of Marketing, 60, 4, 7-18.

GOUNARIS, SP. (2005): Trust and commitment influences on customer retention: insights from business-to-business services. Journal of Business Research, 58, 2, 126-140.

GRÖNROOS, C. (1997): From marketing mix to relationship marketing towards a paradigm shift in marketing. Management Decision, 35, 4, 839-843.

GUSTAFSSON, A., JOHNSON, M.D. and ROOS, I. (2005): The effects of customer satisfaction, relationship commitment dimensions, and triggers on customer retention. Journal of Marketing, 69, 4, 210-218.

HENNIG- THURAU, T. and KLEE, A. (1997): The impact of customer satisfaction and relationship quality on customer retention: a critical reassessment and model development. Psychology \& Marketing, 14, 8, 737-64.

HOMER, P.M. and KAHLE, L. R. (1988): A structural equation test of the value-attitudebehavior hierarchy. Journal of Personality and Social Psychology, 54, 4, 638-646.

KELLER, K.L., and LEHMANN, D.R. (2006): Brands and branding: research findings and future priorities. Marketing Science, 25, 6, 740-59.

LINDEMAN, M. and VERKASALO, M. (2005): Measuring values with the short Schwartz's value survey. Journal of Personality Assessment, 85, 2, 170-178.

MCCRACKEN, G. (2005): Culture and Consumption II: Markets, Meaning, and Brand Management. Bloomington :Indiana University Press.

MEYER, J. P., STANLEY, D. J., HERSCOVITCH, L. and TOPOLNYTSKY, L. (2002): Affective, continuance, and normative commitment to the organization: a meta-analysis of antecedents, correlates, and consequences. Journal of Vocational Behavior, 61, 1, $20-52$.

MILFONT, T.L., DUCKITT, J., WAGNER, C. (2010): A cross-cultural test of the valueattitude-behavior hierarchy. Journal Of Applied Social Psychology, 40, 11, 2791-2813.

MORWITZ, V. G. (1997): Why consumers don t always accurately predict their own future behavior. Marketing Letters, 8, 1, 57-70.

NEWMAN, JW. and WERBE, RA. (1973): Multivariate analysis of brand loyalty for major household appliances. Journal of Marketing Research, 10, 404-409.

PAUL, M., HENNIG- THURAU, T., GREMLER, DD., et al. (2009): Toward a theory of repeat purchase drivers for consumer services. Journal of the Academy of Marketing Science, $37,2,215-237$.

REICHHELD, F. F. (1996): The loyalty effect. Cambridge, Cambridge, MA: Harvard Business School Press.

REYNOLDS, T. J., DETHLOFF, C. and WESTBERG, S. J. (2001): Advancements in laddering. In: Reynolds T. J. \& Olson J. C. (Eds.): Understanding Consumer Decision Making, The Means-end Approach to Marketing and Advertising Strategy. Lawrence Erlbaum Associates, Mahwah, 92-118.

ROS, M., SCHWARTZ, S. H. and SURKISS, S. (1999): Basic individual values, work values, and the meaning of work. Applied Psychology: An International Review, 48, 1, 49-71.

ROSENBERG, L. J. and CZEPIEL, J. A. (1984): A marketing approach to customer retention. Journal of Consumer Marketing, 1, 45-51.

SCHWARTZ, S. and BOEHNKE, K. (2004): Evaluating the structure of human values with confirmatory factor analysis. Journal of Research in Personality, 38, 3, 230-255.

SHIM, S. and EASTLICK, M. A. (1998): The hierarchical influence of personal values on mall shopping attitude and behavior. Journal of Retailing, 74, 1, 139-160.

SJÖBERG, A. and SVERKE, M. (2000): The interactive effect of job involvement and organizational commitment on job turnover revisited: a note on the mediating role of turnover intention. Scandinavian journal of psychology, 41, 3, 247-252.

ZAICHKOWSKY, J. L. (1994): The personal involvement inventory - reduction, revision, and application to advertising. Journal Of Advertising, 23, 4, 59-70. 